\title{
Unidirectional valve malfunction by the breakage or malposition of disc -two cases report -
}

\author{
Chol Lee ${ }^{1}$ Kyu Chang Lee ${ }^{2}$, Hye Young Kim², Mi Na Kim², Eun Kyung Choi ${ }^{2}$, Ji-Sub Kim², \\ Won Sang Lee ${ }^{2}$, Myeong Jong Lee ${ }^{2}$, and Hyung Tae Kim ${ }^{3}$
}

Department of Anesthesiology and Pain Medicine, ${ }^{1}$ Wonkwang University College of Medicine, Iksan, ${ }^{2}$ Konkuk University School of Medicine, Chungju, ${ }^{3}$ Presbyterian Medical Center, Jeonju, Korea

Malfunction of the unidirectional valve in a breathing circuit system may cause hypercapnia from the rebreathing of expired gas, ventilation failure, and barotrauma. Capnography is a useful method for monitoring the integrity of the unidirectional valve. We experienced two cases of malfunction of a unidirectional valve which caused leakage and reverse flow, diagnosed early as a change of the capnographic waveform. One case was caused by expiratory unidirectional valve breakage. The other was caused by an incorrectly-assembled inspiratory unidirectional valve. (Korean J Anesthesiol 2013; 65: 337-340)

Key Words: Capnography, Hypercapnia, Unidirectional valve.

A semiclosed circle system is a commonly used breathing circuit for general anesthesia because of its economy, easy control of humidity and temperature, and reduced chance of contamination of the operating room with anesthetic gas [1]. However, malfunction of either the inspiratory or expiratory unidirectional valve can produce an inappropriate absorption of carbon dioxide, leakage, or obstruction of breathing circuit [2-4]. All of these conditions can be fatal. Herein, we report two cases of unidirectional valve malfunction which were discovered by capnography and rectified following correction of the valves.

\section{Case Reports}

\section{Case 1}

A 46-year-old-female was scheduled for laparoscopic subtotal hysterectomy due to uterine myoma in our hospital. The preoperative laboratory findings were all within the normal ranges except for low hemoglobin of $9.0 \mathrm{~g} / \mathrm{dl}$. The patient was premedicated with intramuscular injection of glycopyrrolate 0.2 $\mathrm{mg}$ and midazolam $2 \mathrm{mg} 30$ minutes before induction of anesthesia. When the patient arrived at the operating room, blood

Received: June 18, 2012. Revised: August 31, 2012. Accepted: September 3, 2012.

Corresponding author: Myeong Jong Lee, M.D., Ph.D., Department of Anesthesiology and Pain Medicine, Konkuk University Chungju Hospital, 620-5, Kyohyun 2-dong, Chungju 380-704, Korea. Tel: 82-43-840-8290, Fax: 82-43-843-9251, E-mail: gooddr21@naver.com

(c) This is an open-access article distributed under the terms of the Creative Commons Attribution Non-Commercial License (http:// creativecommons.org/licenses/by-nc/3.0/), which permits unrestricted non-commercial use, distribution, and reproduction in any medium, provided the original work is properly cited. 
pressure was $140 / 80 \mathrm{mmHg}$, heart rate 90 beats/min, respiratory rate 18 times/min, and $\mathrm{SpO}_{2} 98 \%$. After a normal test of preanesthetic leak test by closing the pop-off valve, occluding the Y-piece, and pressurizing the circuit to $30 \mathrm{cmH}_{2} \mathrm{O}$ with the oxygen flush valve and flow test by using the ventilator and a breathing bag attached to the "Y"-piece as described in the 1993 FDA Anesthesia Apparatus Checkout Recommendations [5] on the breathing circuit, propofol $120 \mathrm{mg}$ and rocuronium $30 \mathrm{mg}$ were given intravenously, followed by uneventful endotracheal intubation. After intubation, $\mathrm{SpO}_{2}$ was $99 \%$ and end-tidal $\mathrm{CO}_{2}$ $\left(\mathrm{ETCO}_{2}\right)$ measured through a previously calibrated side stream capnometer (S/5 ${ }^{\mathrm{TM}}$ Anesthesia Monitor, GE Healthcare, Finland) was $34 \mathrm{mmHg}$. The anesthesia was maintained with $\mathrm{O}_{2} 1.5 \mathrm{~L} /$ min, air $2.5 \mathrm{~L} / \mathrm{min}$, sevoflurane $2-3 \mathrm{vol} \%$, and remifentanil $0.2-$ $0.5 \mu \mathrm{g} / \mathrm{kg} / \mathrm{min}$. The anesthesia ventilator (Narcomed 2B, Dräger, Germany) was set at volume control mode (tidal volume 500 $\mathrm{ml}$, respiratory rate 10 times/min, $\mathrm{I} / \mathrm{E}$ ratio $1: 2$ ). Systolic blood pressure was maintained at $100-150 \mathrm{mmHg}$, diastolic pressure at $60-90 \mathrm{mmHg}$, heart rate at 50-90 beats/min. About $10 \mathrm{~min}$ utes after the anesthesia began, $\mathrm{ETCO}_{2}$ suddenly increased to $52 \mathrm{mmHg}$ and $\mathrm{P}_{\mathrm{I}} \mathrm{CO}_{2} 30 \mathrm{mmHg}$ was noted (Fig. 1). It was the second general anesthesia of the day in this operating room. In addition, during the first 10 minutes, the capnography wave form was normal. Therefore, we initially suspected an erroneous capnometry reading and recalibrated. Breath sounds were clear and bilaterally equal. Since the core temperature measured using a Thermoscan ${ }^{\circledR}$ (infrared tympanic thermometer IRT4020, Braun, Germany) was normal range $\left(36.4^{\circ} \mathrm{C}\right)$, malignant hyperthermia was ruled out. Carbon dioxide absorbent had not changed color. This implied the possibility of rebreathing. Blood pressure was $115 / 62 \mathrm{mmHg}$ and heart rate was 85 beats/min.

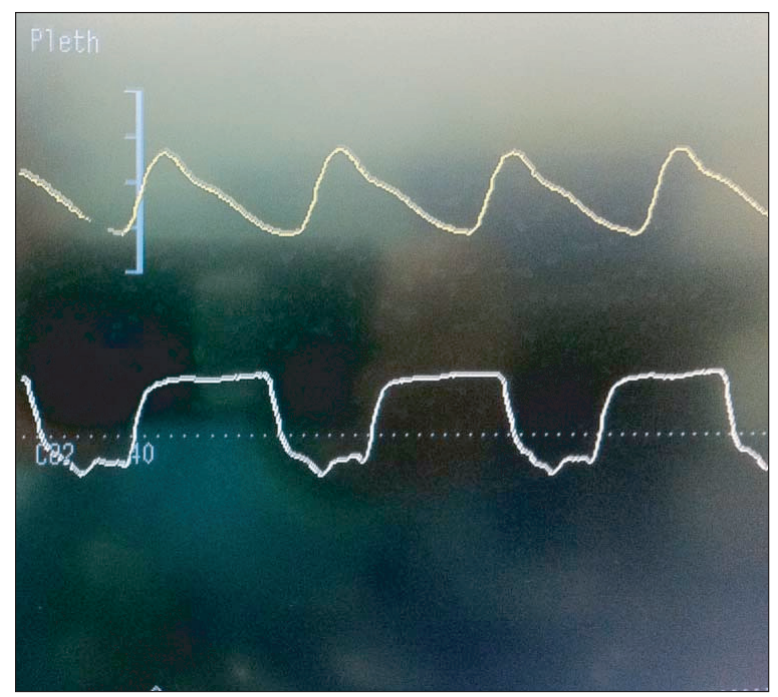

Fig. 1. The capnogram showing that both inspiratory and expiratory $\mathrm{CO}_{2}$ are increased (lower graph).
When the breathing system was rechecked, breakage of the expiratory unidirectional valve through transparent dome, which is divided into three pieces, was discovered (Fig. 2). After replacement of the broken disc by a new one, the capnogram waveform returned to normal. The surgery was completed smoothly and the patient had an uneventful recovery.

\section{Case 2}

A 23-year old man was admitted for tonsillectomy to our hospital. The preoperative laboratory findings were all within normal limits. The patient was premedicated with intramuscular injection of glycopyrrolate $0.2 \mathrm{mg}$ and midazolam $2 \mathrm{mg} 30$ minutes before induction of anesthesia. When the patient arrived at the operating room, blood pressure was $110 / 70 \mathrm{mmHg}$, heart rate 61 beats/min, respiratory rate 14 times/min, and $\mathrm{SpO}_{2}$ 98\%. After a normal preanesthetic leak test by closing the popoff valve, occluding the Y-piece, and pressurizing the circuit to $30 \mathrm{cmH}_{2} \mathrm{O}$ with the oxygen flush valve and flow test by using the ventilator and a breathing bag attached to the "Y"-piece as described in the 1993 FDA Anesthesia Apparatus Checkout Recommendations [5] on the breathing circuit, propofol 140 $\mathrm{mg}$ and rocuronium $30 \mathrm{mg}$ were given intravenously, followed by an uneventful endotracheal intubation. The $\mathrm{SpO}_{2}$ was $100 \%$ and $\mathrm{ETCO}_{2}$ measured through a sidestream capnometer $\left(\mathrm{S} / 5^{\mathrm{TM}}\right.$ Compact Anesthesia Monitor, Datax-Ohmeda, Finland) was 38 $\mathrm{mmHg}$ after intubation. Following confirmation that there were no problems with ventilation in both lungs, a tube was fixed in the area that was $23 \mathrm{~cm}$ away from the incisor. The anesthesia ventilator (Aestiva/5, Datex-Ohmeda, Madison, USA) was set at volume control mode (tidal volume $600 \mathrm{ml}$, respiratory rate 12 times/min, I/E ratio $1: 2$ ). At that time, $\mathrm{ETCO}_{2}$ increased to 46 $\mathrm{mmHg}, \mathrm{P}_{\mathrm{I}} \mathrm{CO}_{2}$ of $4 \mathrm{mmHg}$, and a gradually sloping descending

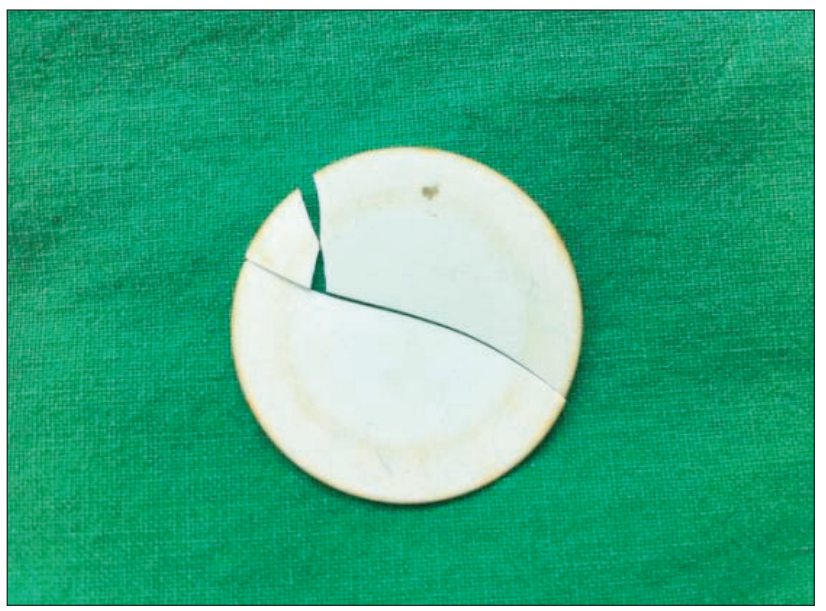

Fig. 2. The broken expiratory valve. 


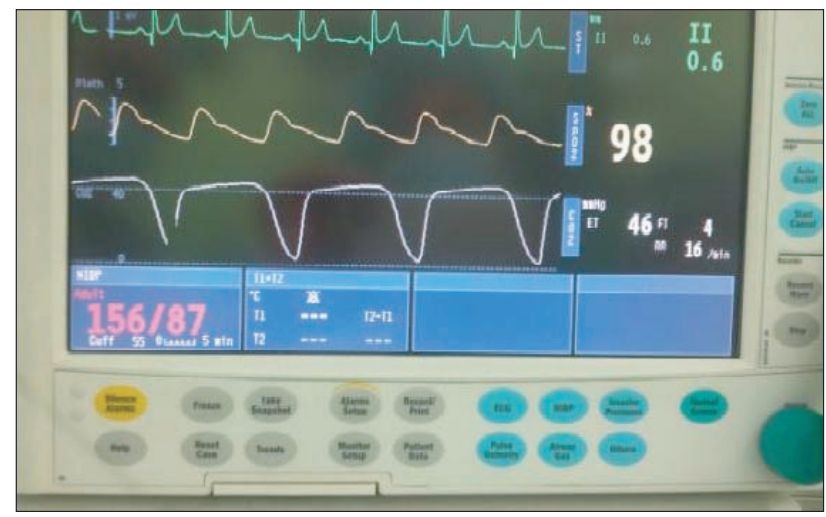

Fig. 3. The capnogram showing a gradually sloping descending limb, elevated inspired $\mathrm{CO}_{2}$ of $4 \mathrm{mmHg}$, and $\mathrm{ETCO}_{2}$ of $46 \mathrm{mmHg}$ (lower graph). ET: endtidal.

limb of inspiratory phase were noted, which implied inspiratory valve malfunction (Fig. 3). Blood pressure was 156/87 $\mathrm{mmHg}$ and heart rate was 75 beats/min. When we inspected the inspiratory valve through the transparent dome, the disc was not located in the center, horizontally. We disassembled the unidirectional valve component right away, which revealed an improper orientation of disc and disc locking apparatus (Fig. 4). After correction, the capnogram waveform returned to normal. The surgery was completed smoothly and the patient had an uneventful recovery.

\section{Discussion}

Inspiratory and expiratory unidirectional valves permit gas flow in one direction only in the semiclosed circle breathing system. Unidirectional valve malfunction can occur in case of a broken disc, replacement with a different size, or a disc that is sticky due to the moisture or improper orientation. These can cause failure to open or close, leading to hypercapnia, ventilation failure, or barotrauma as the degree of malfunction $[2,3,6,7]$.

The present two cases represented a failure to close the unidirectional valve. If the expiratory unidirectional valve fails to close completely, then previously exhaled gas, which is high in $\mathrm{CO}_{2}$ in the expiratory limb, will be rebreathed with each inspiration, leading to hypercapnia, markedly elevating both inspiratory and expiratory segments of the $\mathrm{CO}_{2}$ waveform [4]. It can cause hypertension, tachycardia, and increased intracerebral pressure. Because we discovered the problems within a few minutes, there were no vital sign changes. In case 1 , we did not suspect unidirectional expiratory valve malfunction at first because there was no abnormal $\mathrm{CO}_{2}$ waveform at the prior general anesthesia and it was normal at the first 10 minutes of this anesthesia. We first thought that the error was in the capnometer, and calibrated again. To rule out increasing metabolic

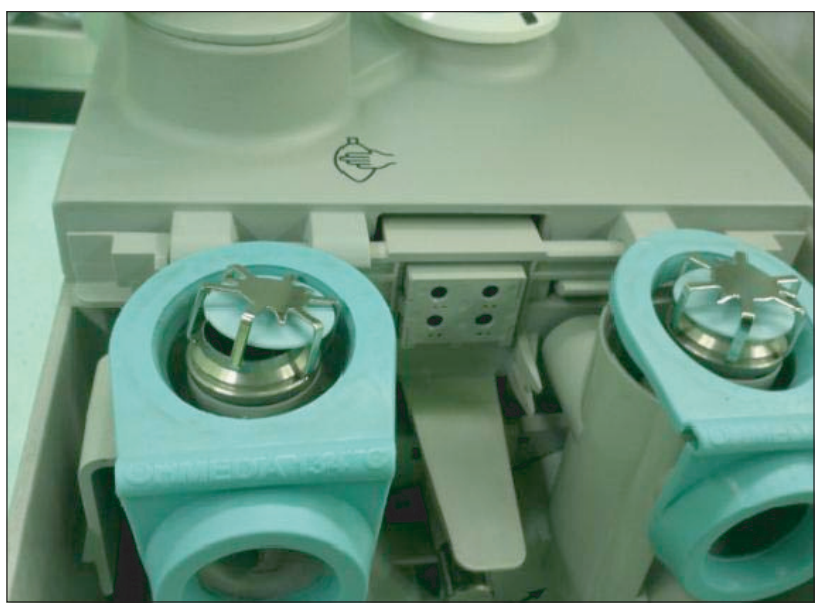

Fig. 4. Properly connected expiratory unidirectional valve (Right) and improper orientation of disk and disc locking apparatus (Left). Note that the disk locking apparatus of which its foot is not put on the groove of valve.

rate of patient by malignant hyperthermia, we checked the body temperature, but it was within normal range of temperature. Therefore, we suspected the cause of abnormal $\mathrm{CO}_{2}$ waveform to be rebreathing of the breathing circuit. At that time, we found the broken expiratory valve disc through the transparent dome. When a disc breaks suddenly in the midst of anesthesia like our case 1 , capnography can be used to identify unidirectional valve incompetence. Expiratory valve malfunction is more frequent than the inspiratory one due to its exposure to a humid alveolar gas [8].

When an expiratory unidirectional valve is sticky, it can cause obstruction of the breathing system, which can cause exhalation failure, leading to pulmonary barotraumas and pneumothorax [3,7]. Yang et al. [3] reported the case involving a misunderstood situation of failed ventilation caused by sticky expiratory unidirectional valve. If this event occurs during anesthesia, endotracheal tube obstruction, bronchial spasm, or malfunction of the anesthesia delivery system need to be considered. Especially, when the sound of air leakage caused by disconnection of endotracheal tube from the anesthetic circuit is heard and a positive pressure ventilation is easily conducted using the other resuscitation bags, an anesthesia delivery system obstruction, including the unidirectional valve, bacterial filter, and scavenging pathway should be suspected $[3,9,10]$. This situation can arise suddenly in the middle of anesthesia. Therefore, $\mathrm{CO}_{2}$ wave and airway pressure should be continuously monitored.

If the inspiratory valve fails to close, $\mathrm{CO}_{2}$ gas is usually detected only at the beginning of inspiration because it would permit the exhaled $\mathrm{CO}_{2}$ to enter the $\mathrm{CO}_{2}$ free inspiratory limb of the breathing circuit, and to be breathed in by the patient during the next inspiratory period [11]. As in case 2, the capnogram will display 
a prolonged plateau, gradually sloping descending limb without approaching the zero baseline $[12,13]$. When the incompetence of inspiratory valve is mild, it is not a severe problem. But if it is severe or the operation time is long, profound hypercapnia can occur. After case 2, we dissembled all unidirectional valve disc locking apparatuses in our hospital and examined them closely. Only case 2's disc locking apparatus of inspiratory unidirectional valve was loosely-fitting, so it could be easily mispositioned while reassembling. In case 2, the surgery was the first one done on Monday. It was presumed that the duty nurse of the prior day assembled the valve improperly after cleaning. A centrally and horizontally-located disc which at first covers the whole orifice of inspiratory valve could to move peripherally enough to make a gap as the induction of anesthesia goes on. Loose disc locking apparatus should be repaired to maintain the correct alignment.

Currently, unidirectional valve function can be tested using either the breathing method [11], the anesthesia machine valve tester [14], the pressure decline method and modified pressure decline method [15]. Some new anesthesia workstations allow the machine to automatically check for functionality of electronic, mechanical, and pneumatic components including unidirectional valves. But, automatic check of ventilator does not confirm valve integrity [6]. Therefore, it is still important for the operator to visually inspect the valves to ensure they move appropriately not only before induction but also in the middle of anesthesia especially unidirectional valve malfunction is suspected like our cases.

Over the years, the anesthesia delivery system has evolved to a complex multisystem workstation. To prevent mishaps, anesthesia care providers must be aware of the functional anatomy of the anesthesia workstation and current guidelines for developing institution-specific checkout procedures.

In conclusion, two cases of abnormal $\mathrm{CO}_{2}$ wave form caused by unidirectional valve malfunction and early detection without any complications are presented. These cases are good examples of the significance of $\mathrm{ETCO}_{2}$ monitor to verify the malfunction of unidirectional valve during general anesthesia.

\section{Acknowledgments}

This study was suppported by Wonkwang University in 2013.

\section{References}

1. Miller RD. Miller's anesthesia. 7th ed. Philadelphia, Elsevier Churchill Livingston. 2010, pp 692-5.

2. Lin SL, Yeh CC, Lu CH, Ho ST, Wong CS. Hypercapnia due to rupture of the unidirectional valve in the inspiratory limb of the breathing system after induction of general anesthesia--a case report. Acta Anaesthesiol Sin 2003; 41: 139-43.

3. Yang HJ, Song JE, Lee JY, Kim MK, Gill HJ, Park JH, et al. Expiratory valve malfunction detected immediately after endotracheal intubation -a case report-. Korean J Anesthesiol 2007; 53: 774-7.

4. Pyles ST, Berman LS, Modell JH. Expiratory valve dysfunction in a semiclosed circle anesthesia circuit--verification by analysis of carbon dioxide waveform. Anesth Analg 1984; 63: 536-7.

5. Food and Drug Administration. Anesthesia apparatus checkout recommendation. Rockville, MD, Food and drug administration. 1993.

6. Kim TH, Park YS, Lee EH, Jeong YB, Choi IC. Ventilation impairment caused by upside-down connected unidirectional valves -a case report-. Korean J Anesthesiol 2008; 55: 736-9.

7. Dean HN, Parsons DE, Raphaely RC. Case report: Bilateral tension pneumothorax from mechanical failure of anesthesia machine due to misplaced expiratory valve. Anesth Analg 1971; 50: 195-8.

8. Han SR, Ho CS, Jin CH, Liu CC. Unexpected intraoperative hypercapnia due to undetected expiratory valve dysfunction--a case report. Acta Anaesthesiol Sin 2003; 41: 215-8.

9. Aarhus D, Soreide E, Holst-Larsen H. Mechanical obstruction in the anaesthesia delivery-system mimicking severe bronchospasm. Anaesthesia 1997; 52: 992-4.

10. O'Connor DE, Daniels BW, Pfitzner J. Hazards of anaesthetic scavenging: case reports and brief review. Anaesth Intensive Care 1982; 10: 159.

11. Kim JM, Kovac AL, Mathewson HS. A method for detection of incompetent unidirectional dome valves: a prevalent malfunction. Anesth Analg 1985; 64: 745-7.

12. Bhavani-Shankar K, Philip JH. Defining segments and phases of a time capnogram. Anesth Analg 2000; 91: 973-7.

13. Miller RD. Miller's anesthesia. 7th ed. Philadelphia, Elsevier Churchill Livingston. 2010, pp 1424-9.

14. Eappen S, Corn SB. The anesthesia machine valve tester: a new device and method for evaluating the competence of unidirectional anesthetic valves. J Clin Monit 1996; 12: 305-9.

15. Weigel WA, Murray WB. Detecting unidirectional valve incompetence by the modified pressure decline method. Anesth Analg 2005; 100: $1723-7$. 